\title{
Intramuscular Hemangioma: Enigmatic Dilemma in Diagnosis
}

\author{
${ }^{1}$ Sakshi Kamra, ${ }^{2}$ Keerthilatha M Pai, ${ }^{3}$ Yogesh Chhaparwal
}

\begin{abstract}
Intramuscular hemangiomas (IMHs) occur when the proliferation of blood vessels is found between the skeletal muscle fibers, and they account for less than $1 \%$ of all hemangiomas. We report two cases of IMHs in the rare locations like tongue and temporalis muscle. These hemangiomas should be considered in a differential diagnosis of the soft tissue masses. Radiology plays a pivotal role in the diagnosis of these lesions.
\end{abstract}

Keywords: Hemangioma, Intramuscular, Phleboliths, Temporalis muscle, Tongue.

How to cite this article: Kamra S, Pai KM, Chhaparwal Y. Intramuscular Hemangioma: Enigmatic Dilemma in Diagnosis. J Health Sci Res 2016;7(2):67-70.

Source of support: Nil

Conflict of interest: None

\section{INTRODUCTION}

Hemangioma is a benign soft tissue lesion occurring most commonly in the skin and subcutaneous tissues. ${ }^{1}$ Hemangiomas are hamartomas rather than true neoplasms and are generally composed of vascular spaces arising from endothelial cells and not by grouping of nearby vascular channels. ${ }^{2}$ When the proliferation of blood vessels is found between skeletal muscle fibers, such lesions are called intramuscular hemangioma (IMH), which account for less than $1 \%$ of all hemangiomas. ${ }^{3} \mathrm{~A}$ total of $15 \%$ of IMHs occur in the head and neck region. ${ }^{4}$ Approximately $90 \%$ of IMHs occur before the third decade of life, with no sex predilection..$^{5}$ Phleboliths are calcified thrombi that are a characteristic feature of hemangiomas, occurring in 15 to $25 \%$ of IMHs. ${ }^{4}$ Because of their rarity and unspecified presentations, more than $90 \%$ of cases are misdiagnosed before surgery. ${ }^{5}$ Although standard radiographs are simple and constitute an important

\footnotetext{
${ }^{1}$ Dental Radiologist, ${ }^{2,3}$ Professor

${ }^{1}$ Dental Radiologist, New Delhi, India

${ }^{2,3}$ Department of Oral Medicine and Radiology, Manipal College of Dental Sciences, Manipal, Karnataka, India

Corresponding Author: Sakshi Kamra, Dental Radiologist New Delhi, India, Phone: +917795117864, e-mail: sakshi_ tis2006@yahoo.co.in
}

tool in diagnosing the phleboliths associated with hemangiomas, other diagnostic imaging modalities, such as computerized tomography (CT), magnetic resonance imaging (MRI), and ultrasound, also play a substantial role in the diagnosis of IMH. ${ }^{6}$

We present two cases of IMH. The first was found in the tongue of a 29-year-old man, and the second case presented as a painless mass in the left temporal region of a 32-year-old man.

\section{CASE REPORTS}

\section{Case 1}

A 29-year-old man in good general health presented with a complaint of swelling on the tongue since 8 years, which gradually increased in size to attain the present dimensions (Fig. 1). He did not report any pain, bleeding associated with the swelling, nor any history of trauma to the tongue. He did not report any difficulty in mastication, speech, breathing, altered taste, or general sensation. His medical and family history was unremarkable. On intraoral examination, a bluish swelling approximately $3 \times 3 \mathrm{~cm}$ in size was present on the right side of dorsum of the tongue. It was nontender, fluctuant, compressible with no surface ulcerations. There were no bruits or pulsation present. No anesthesia or paresthesia was reported. Diascopy revealed blanching of the lesion, and other oral findings were not significant, giving a provisional diagnosis of a vascular lesion.

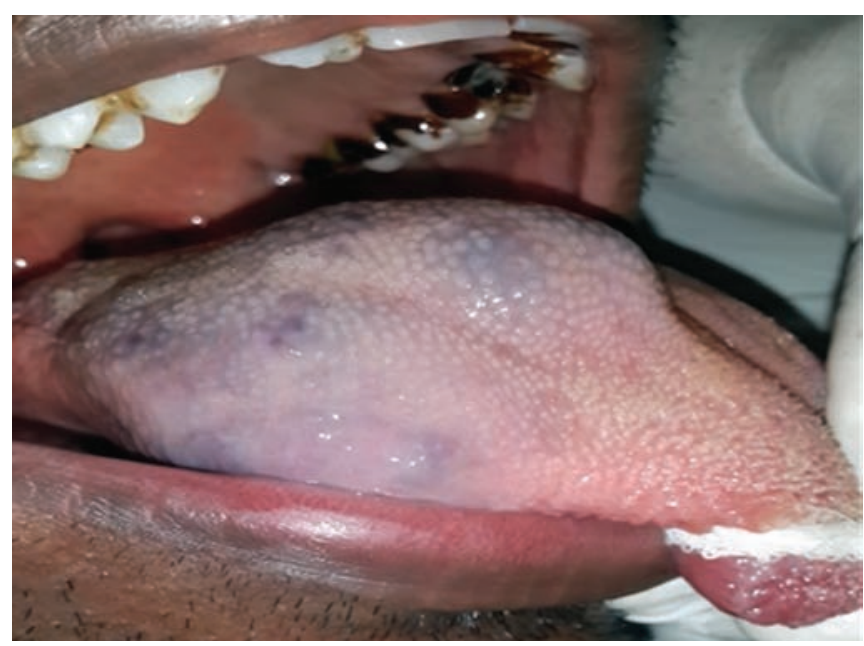

Fig. 1: Clinical picture of swelling on the dorsum and the right ventral aspect of tongue 


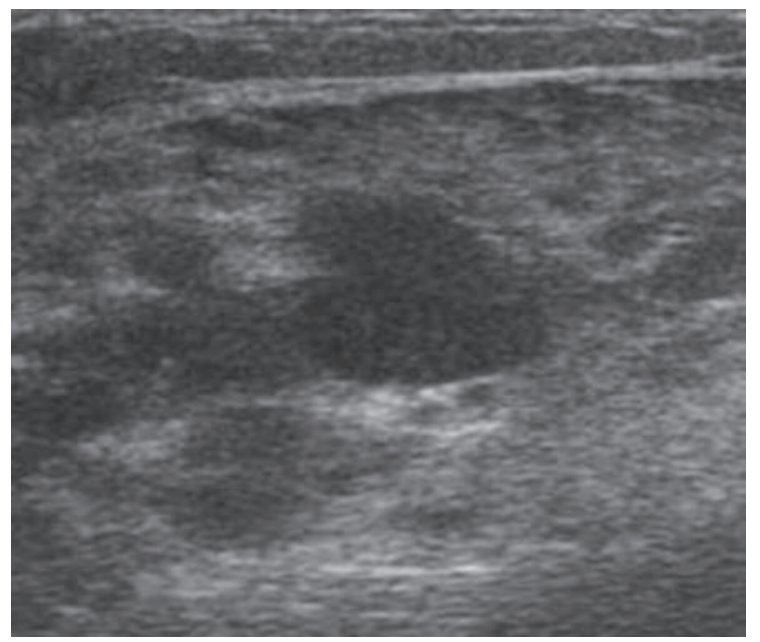

Fig. 2: Ultrasound examination showing lesion with multiple vascular spaces having slow flow and few phleboliths of tongue on right side
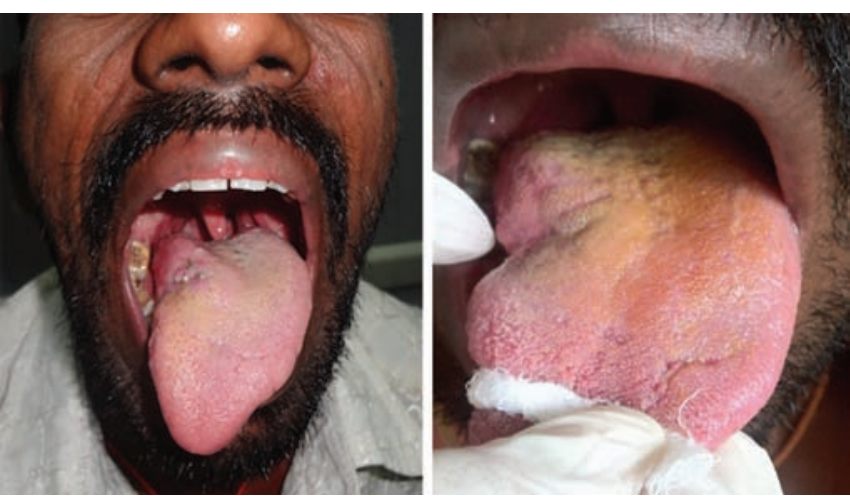

Fig. 4: Clinical picture of follow-up at 2 and 9 months

Panoramic radiograph showed small numbers of round target-like radiopacities projected over the right body of mandible, representing phleboliths present in tongue. Ultrasound examination showed a mass lesion measuring $4.2 \times 2.6 \times 2.8 \mathrm{~cm}$ with multiple vascular spaces having slow flow and few phleboliths involving the right side of the tongue (Fig. 2). Although MRI was advised, patient did not go for it because of financial constraints. Surgical excision was done under general anesthesia without much bleeding, and postoperative period was uneventful (Fig. 3). Histopathology examination showed proliferation of vascular capillaries within the muscle tissue, leading to the diagnosis of IMH. The patient has since been on follow-up and has shown no signs of recurrence or any other changes (Fig. 4). His speech and tongue movements are normal.

\section{Case 2}

A 32-year-old man presented with a bulge in the left temporal region that had been gradually increasing in size during the last 2 years (Fig. 5). There were no trauma or any associated symptoms. Examination revealed a soft, nontender swelling measuring $2 \times 2 \mathrm{~cm}$ in the left temporal
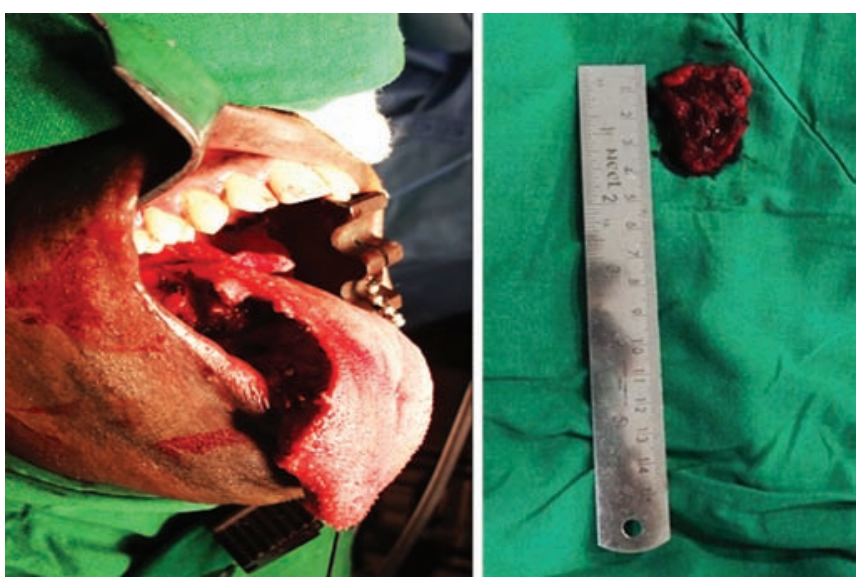

Fig. 3: Intraoperative picture and the excision lesion

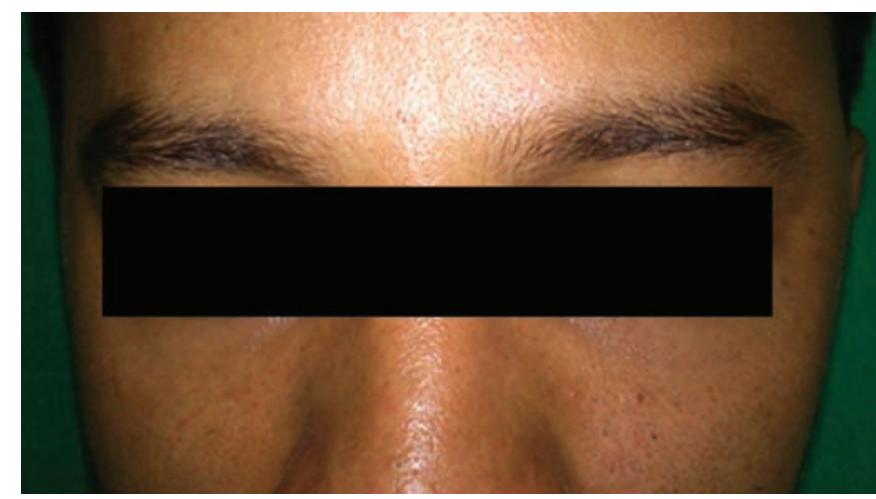

Fig. 5: Clinical picture showing bulge in the left temporal region

region. The overlying skin was normal. Ultrasound and color Doppler examination revealed a well-defined heterogeneous echotexture lesion with internal vascularity measuring $2.7 \times 1 \mathrm{~cm}$ in the left temporalis muscle (Fig. 6). Magnetic resonance imaging scan showed a well-defined altered signal intensity lesion measuring $1.1 \times 1.4 \times 3.0 \mathrm{~cm}$, which was hypointense on T1-weighted image and heterogeneously hyperintense on T2-weighted image showing brilliant postcontrast enhancement within the substance of left temporalis muscle (Fig. 7). Thus, diagnosis of IMH was formulated. Surgical excision was advised, but patient opted for treatment at a later date.

\section{DISCUSSION}

Intramuscular hemangiomas represent $0.8 \%$ of all benign vascular neoplasms. ${ }^{3}$ About $15 \%$ of them occur in the head and neck region, ${ }^{4}$ with the masseter muscle being the most common site, followed by the trapezius and sternocleidomastoid muscles. ${ }^{7}$ Intramuscular hemangiomas of the tongue and temporalis muscle are extremely rare. A thorough search of literature yielded 5 and 24 cases $^{8}$ of IMH of tongue and temporalis muscle respectively. 


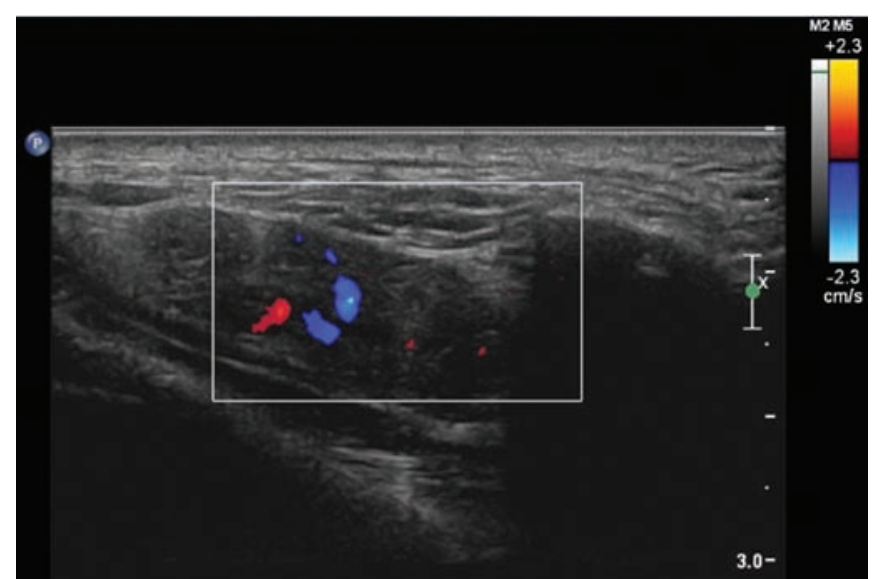

Fig. 6: Color Doppler showing a well-defined heterogeneous echotexture lesion with internal vascularity in the left temporalis muscle

Intramuscular hemangiomas were first labeled by Liston in 1843, and classified in 1972, by Allen and Enzinger depending on the vessel size. ${ }^{9}$ The capillary variant is most common, which represents $68 \%$ of IMHs followed by the cavernous and mixed type with an occurrence of 26 and $6 \%$ respectively. ${ }^{10}$

Intramuscular hemangiomas rarely display clinical symptoms or signs that reveal their vascular nature. There are usually no overlying skin changes, although there may be occasional reddish-blue discoloration. Thrills, bruits, compressibility, and pulsation are usually absent; however, pain can be a feature. ${ }^{11}$ The formation of phleboliths causes no symptoms. Phleboliths are intravascular calcifications, which consist of a mixture of calcium carbonate and calcium phosphate salts. ${ }^{10}$ Radiologically, they have either a radiolucent or a radiopaque core, and repetition of this calcification causes an onion peel-like appearance or concentric rings. ${ }^{6}$ Plain radiographs can show soft tissue calcifications. In addition, other diagnostic imaging modalities, such as ultrasound, CT, MRI, are adjuncts in preoperative diagnosis for this lesion. ${ }^{12}$ Ultrasonography should be the first imaging modality. Color Doppler sonography is especially useful to demonstrate the vascular structures in and around the muscle and has the potential to assess the pathological changes. They present with a well-defined hypoechoic mass with heterogeneous echotexture. ${ }^{13}$ Computerized tomography scan can show the mass as isodense to the skeletal muscle with decreased attenuated areas, and it also demonstrates any calcification or ossification if present. ${ }^{13}$ Magnetic resonance imaging is considered the most useful imaging modality, which demonstrates hyperintensity on T2-weighted images and isointensity on T1-weighted images. ${ }^{12}$

Management of IMH should be individualized to its size, growth rate, anatomic accessibility of the tumor, age of the patient, and cosmetic and functional considerations.

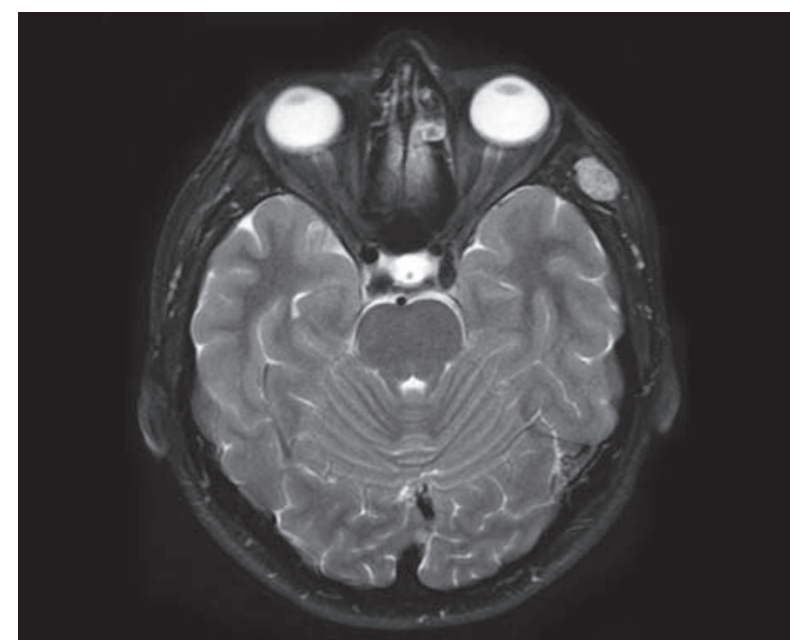

Fig. 7: Magnetic resonance imaging scan showing a well-defined altered signal intensity lesion which is hypointense on T1-weighted image with brilliant postcontrast enhancement within the substance of left temporalis muscle

Many forms of treatment modalities have been suggested, including cryotherapy, radiotherapy, sclerosing agents, and steroids, but the ideal treatment is complete excision of the tumor, thereby eliminating the phlebolith. ${ }^{6}$ Local recurrence rates range from 9 to $28 \%$.?

\section{CONCLUSION}

Intramuscular hemangioma occurring in two unusual locations is reported. Clinical differential diagnosis of soft tissue mass lesions should include vascular lesions. Appropriate imaging should be advised prior to surgical intervention.

\section{ACKNOWLEDGEMENT}

The authors thank Dr Dinesh Kadam, Microvascular Plastic Surgeon, A.J. Institute of Medical Sciences, Mangalore for providing them with the intraoperative pictures for which they are very grateful.

\section{REFERENCES}

1. Bucci T, De Giulio F, Romano A, Insabat L, Califa L. Cavernous haemangioma of the temporalis muscle: case report and review of the literature. ACTA Otorhinolaryngol Ital 2008 Apr;28(2):83-86.

2. Nayak S, Sundharam $S$, Kavitha B. Intra-masseteric haemangioma: a case report. Guident 2012;5(8):89.

3. Kanaya H, Saito Y, Gama N, Konno W, Hirabayashi H, Haruna SI. Intramuscular hemangioma of masseter muscle with prominent formation of phleboliths: a case report. Auris Nasus Larynx 2008 Dec;35(4):587-591.

4. Rossiter JL, Hendrix RA, Tom LW, Potsic WP. Intramuscular hemangioma of the head and neck. Otolaryngol Head Neck Surg 1993 Jan;108(1):18-26.

5. Odabasi AO, Metin KK, Mutlu C, Basak S, Erpek G. Intramuscular hemangioma of the masseter muscle. Eur Arch Otorhinolaryngol 1999;256(7):366-369. 
6. Zengin AZ, Celenk P, Sumer AP. Intramuscular hemangioma presenting with multiple phleboliths: a case report. Oral Surg Oral Med Oral Pathol Oral Radiol 2013 Jan;115(1):32-36.

7. Wolf GT, Daniel F, Krause CJ, Kaufman RS. Intramuscular hemangioma of the head and neck. Laryngoscope 1985 Feb;95(2):210-213.

8. Allen PW, Enzinger FM. Hemangioma of skeletal muscle. An analysis of 89 cases. Cancer 1972 Jan;29(1):8-22.

9. Giudice M, Piazza C, Bolzoni A, Peretti G. Head and neck intramuscular haemangioma: report of two cases with unusual localization. Eur Arch Otorhinolaryngol 2003 Oct;260(9):498-501.
10. Sano K, Ogawa A, Inokuchi T, Takahashi H, Hisatsune K. Buccal hemangioma with phleboliths. Report of two cases. Oral Surg Oral Med Oral Pathol 1988 Feb;65(2): 151-156.

11. Yonetsu K, Nakayama E, Yuasa K, Kanda S, Ozeki S, Shinohara M. Imaging findings of some buccomasseteric masses. Oral Surg Oral Med Oral Pathol Oral Radiol Endod 1998 Dec;86(6):755-759.

12. Afsar FS, Oziz E, Hamdioglu Y, Karasoy I, Uguz B. Intramuscular hemangioma of the masseter muscle in a 9 year old girl. Acta Angiol 2009;13(1):42-46. 